\title{
Morphological Observation of Liquid-Liquid Phase Separated Microporous Membrane Consisting of High Density Polyethylene and Styrene/Hydrogenated Butadiene Diblock Copolymer by Transmission Electron Microscopy
}

\author{
Hatsuyo Ohyanagi, Miki Inamoto, Fujiharu Nagoya, Sigenobu Matsuda, and Kunihiko Okajima \\ Central Research Laboratory, Asahi Chemical Industry Co., Ltd., 11.7 Hacchownawate, Takatsuki, Osaka 569. \\ Japan
}

\begin{abstract}
The polyethylene / dialkylphthalate system was found to exibit liquid-liquid phase separation thermodynamically and microporous membrane consisting of independent spherical-like pore could be prepared by gradual cooling of this system. The addition of styrene hydrogenated butadiene di-block copolymer (SHB) to the above system resulted in the very homogeneous pore structure by spinodal decomposition. For the purpose of clarifying the role of SHB on the pore-structure formation, a preferential staining of SHB by rutenium tetraoxide was made and the membrane was observed by TEM. SHB exists as if encapsulating the pore composed of HDPE backbone and works as a polymeric surfactant between polyethylene-rich and -poor phases and hinders the coarsening of the phase-separated structure.
\end{abstract}

\section{Introduction}

We [1] recently succeeded in preparing a liquid-liquid phase separated microporous high density polyethylene (HDPE) membrane from a HDPE / dialkyl-phthalate system. It was found that the addition of styrene/hydrogenated butadiene diblock copolymer (SHB) to the above system resulted in the very homogeneous pore structure formed by spinodal decomposition. Therefore, it is important to examine the morphology of the membrane to clarify the role of SHB in the mechanism of the microporous $P E$ membrane formation.

A transmission electron microscopy (TEM) seems most suitable for observation of microporous membranes by staining methods. Hydrogen permanganate (2], chlorosulfuric acid / uranyl acetate [3] and ruthenium tet. raoxide $\left(\mathrm{RuO}_{4}\right)$ [4.6] have been proposed as agents to stain $\mathrm{PE}$ and polypropylene (PP). Of these staining agents, $\mathrm{RuO}_{4}$ stains polymers having both saturated and unsaturated bonds, including benzene ring $(4,5]$, accompanying oxidation reaction [6]. It is anticipated that $\mathrm{RuO}_{4}$ may stain preferentially SHB unit in the present HDPE / SHB system where styrene unit exists as unsatu. rated bond. In this note, we attempted to elucidate the morphological role of SHB component in HDPE/SHB membrane by TEM observation using $\mathrm{RuO}_{4}$ as a staining agent, and compared the results with HDPE membrane without SHB as a control.

\section{Experimental}

\subsection{Materials and Microporous Membrane}

HDPE $\left(\mathrm{Mw}=2.8 \times 10^{5} . \mathrm{Mw} / \mathrm{Mn}=6.7\right)$ was supplied from Asahi Chemical Industry Co., Ltd. SHB $(\mathrm{Mn}=8.7 \times$ $10^{4}$, styrene content ; $25 \mathrm{wt} \%, 1,2$ bondage contént ; $13.2 w t \%$, hydrogenation : $98 \%$ ) was synthesized in $\mathrm{R} \&$ D division of Synthetic Rubber Section. Asahi Chemical Industry Co., Ltd. A mixture of HDPE / SHB ( $=80 / 20$, $\mathrm{w} / \mathrm{w}$ ) was mechanically blended with diisodecylphthalate (DIDP). The polymer concentration was adjusted to $40 w t \%$ at $230{ }^{\circ} \mathrm{C}$. The mixture was pressed at the same temperature and then gradually cooled down by circulation of water controlled at $20^{\circ} \mathrm{C}$. DIDP in the membrane was extracted with dichloromethane. The resultant mem. brane was subject to TEM observation without any stretching. A porous HDPE membrane without SHB component was prepared in a similar manner as described above, except that abrupt cooling was done instead of gradual cooling to give a mechanical strength of the mem. 
brane standable for ultrathin sectioning for TEM observation. The gradual cooling for the latter membrane resulted in one with large pores, failed in ultrathin sectioning. Bright field image of TEM photographs was taken under the same exposure time except that the HDPE stained with $\mathrm{RuO}_{4}$ for 10 minutes, was exposed to much longer time to make contrast clear.

\subsection{Staining and TEM Observation}

Sample membranes with $100 \mu \mathrm{m}$ thick were capsu lated with an epoxy resin and the resin was polymerized in an oven for 15 hours at $60^{\circ} \mathrm{C}$. The obtained resin block was trimmed and the ultrathin sections were pre. pared with an ultramicrotome (Reichert-Nissei ultracut $\mathrm{N}$ ) cooled at $-160^{\circ} \mathrm{C}$ in a cryochamber (Reichert-Nissei FC4D). The sections obtained (thickness ; $50 \sim 100 \mathrm{~nm}$ ) were collected on a copper grid by the usual drying method. The sections on the grid were stained in the vapor phase of aqueous $0.5 \mathrm{wt} \% \mathrm{RuO}_{4}$ solution in a glass vessel for 10, 30 and 60 minutes in a draft chamber at $25^{\circ} \mathrm{C}$. After carbon spattering, bright field TEM observation was carried out using JEM-1200EX at an accelerated voltage of $80 \mathrm{kV}$

\subsection{SEM and SPM Observation}

Scanning electron microscopic (SEM) observation for the two membranes, which had been fractured in liquid $\mathrm{N}_{2}$ and then gold-coated by spattering was also carried out in a field emission type of SEM (S.800, Hitachi, Japan) at an accelerated voltage of $5 \mathrm{kV}$.

Scanning probe microscopy (SPM) for the two membranes was also made to examine their morphology in

a)

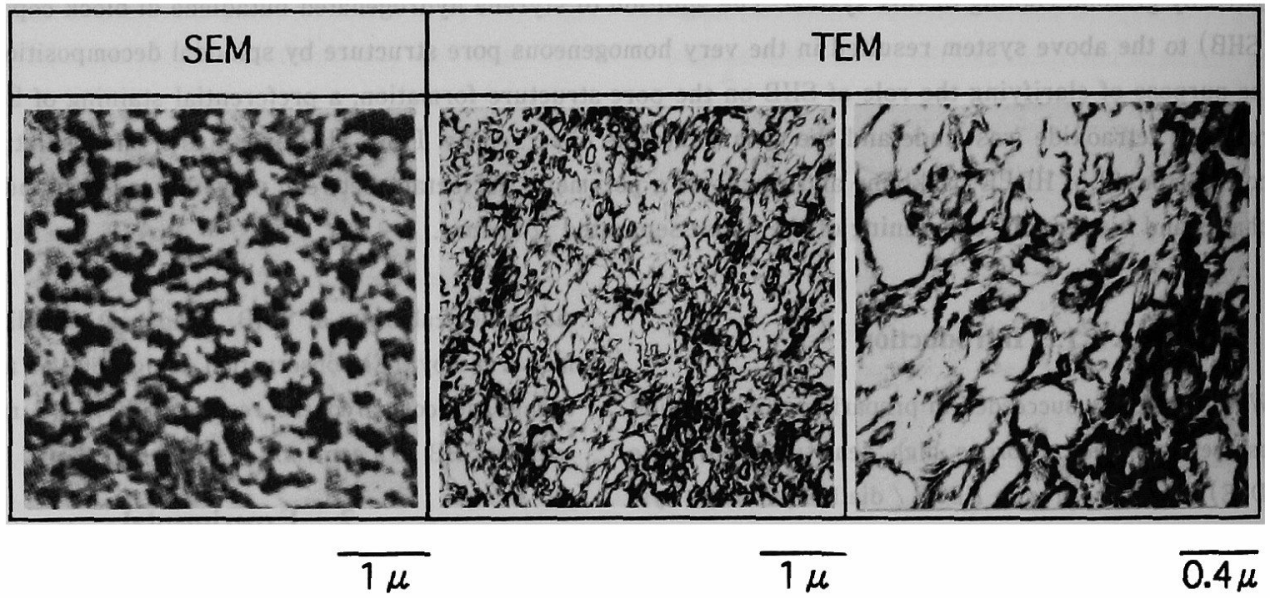

b)

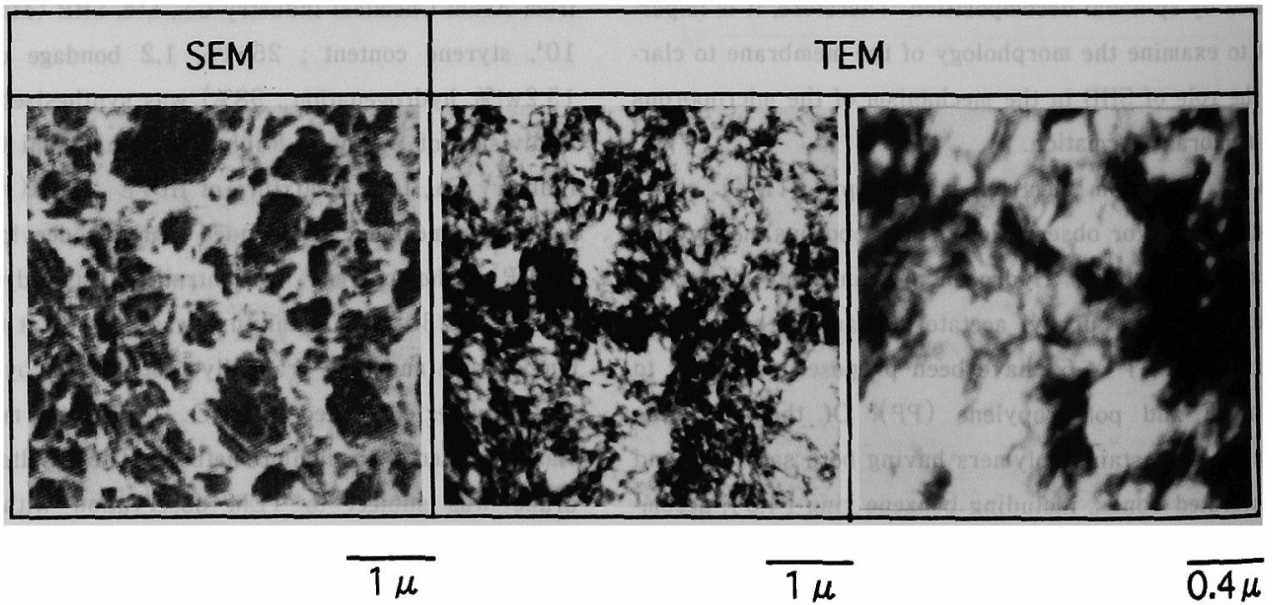

Fig. 1 SEM and the TEM micrographs of (a) HDPE / SHB and (b) HDPE membranes. Staining time of RuO4 for TEM samples was 10 minutes. 
more detail using a SPM instrument (Nano Scope III of Digital Instruments Corp.). The measurements were performed in air at $25^{\circ} \mathrm{C}$ in tapping mode with frequency of around $300 \mathrm{kHz}$. A cantilever used here is made of single crystal silicone with cone angle of $20^{\circ}$, lever length of $125 \mu \mathrm{m}$, radius of the tip curvature of $10 \mathrm{~nm}$, and modulus of $20 \mathrm{~N} / \mathrm{m}$.

\section{Results and Discussion}

As a preliminary experiment, the unstretched microporous membranes were stained by $\mathrm{RuO}_{4}$ vapor. It was found that HDPE / SHB microporous membrane is stained much faster than HDPE, giving a basis for stain- ing method with an advantage that SHB is more stained by $\mathrm{RuO}_{4}$ than HDPE.

Fig. 1 shows SEM, TEM micrographs of HDPE / SHB (a) and HDPE (b) membranes. In SEM micrographs, the white part denotes polymer solid, while the dark one the pores. They are opposite in the TEM micrographs of $\mathrm{RuO}_{4}$ stained specimens. Many black circular lines in the TEM micrographs of HDPE/SHB are seen suggesting that the SHB parts encapsulate the pores. The width of 20 $40 \mathrm{~nm}$ of the black line is very close to the chain length of styrene part of SHB. On the other hand, such a mor phology was not observed for HDPE membrane. This im plies that HDPE was not stained, even though it was ex-
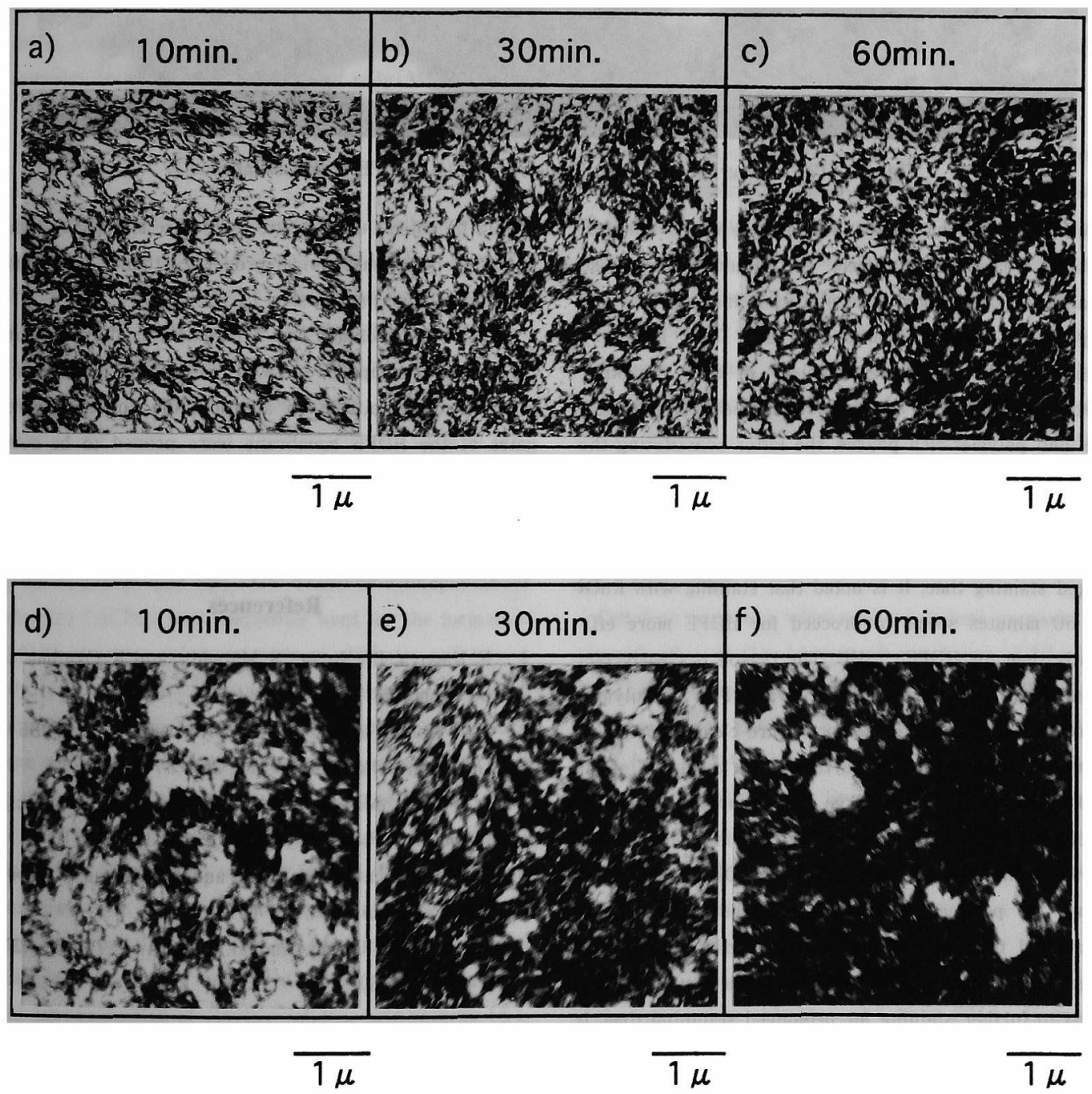

Fig. 2 Bright field image of TEM micrographs with the prolonged staining time: (a), (d) 10 minutes; (b), (e) 30 minutes; (c), (f) 60 minutes. (a)-(c) HDPE / SHB membrane, (d)-(f) HDPE membrane. 


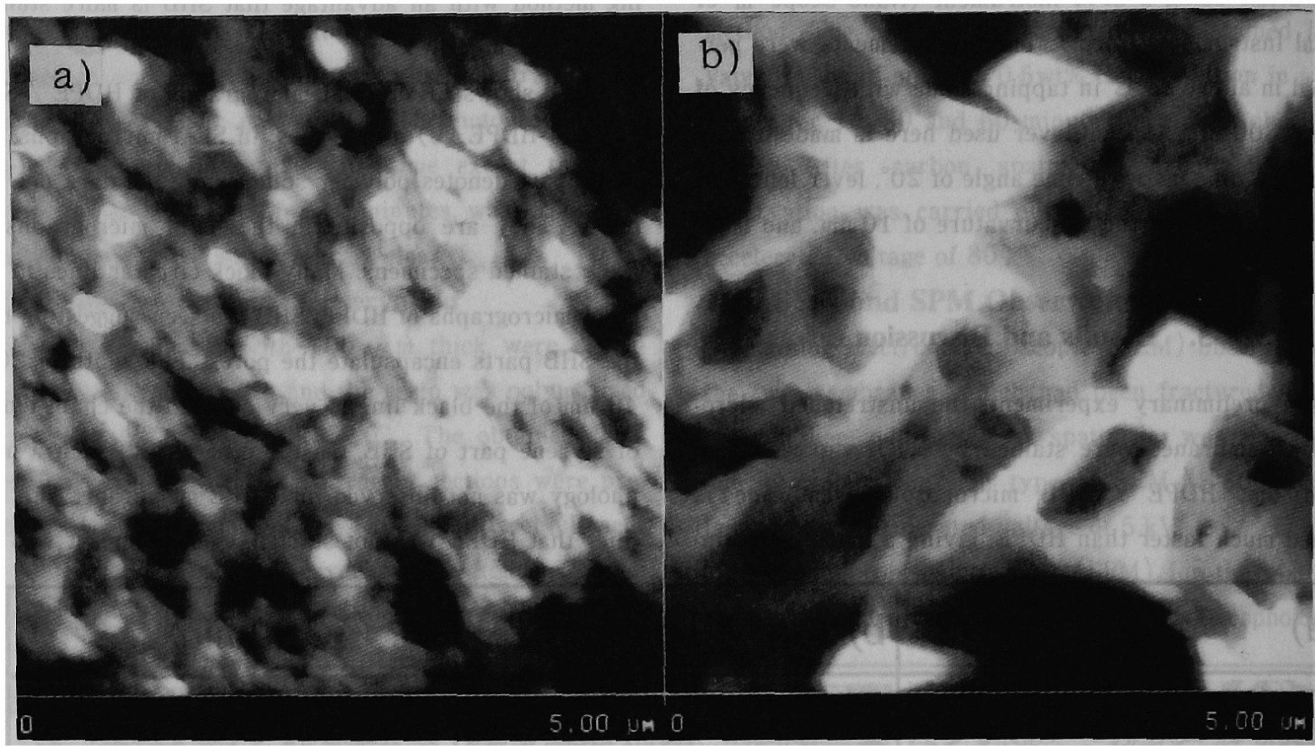

Fig. 3 SPM photographs: (a) HDPE membrane, (b) HDPE / SHB membrane.

posed for very long photoexposure time of 10 minutes. This is reasonable because the liquid-liquid phase separation by spinodal decomposition induces that the polymer-lean phase becomes pore and DIDP has very strong affinity to stryrene moiety in SHB. In other words, SHB is located in the boundary between polymerlean and polymer-rich phases, the latter constituting the polymer aggregates.

Fig. 2 clearly indicates that both HDPE / SHB and HDPE microporous membranes are well stained at prolonged staining time. It is noted that staining with $\mathrm{RuO}_{4}$ for 60 minutes seems to proceed for HDPE more efficiently than for HDPE / SHB. The reason is clearly pictured in the SPM photographs shown in Fig. 3a. Polymer aggregates of the HDPE membrane are clearly composed of many accumulated fine particles with radius of about $100 \mathrm{~nm}$. This gives that large HDPE surface is easy to react with $\mathrm{RuO}_{4}$ when the staining time is prolonged. On the on hand, Fig. $3 \mathrm{~b}$ shows that in HDPE /SHB membrane, the polymer aggregates is composed of densely coagulated fibrillar bundles although some smooth and larger particles are also observed. This structure may resist to further staining for prolonged stainning time. It should be noted that the latter structure might give some basis for better mechanical properties than HDPE mem. brane, as shown previously [1].

Thus, it is concluded that SHB exists as if encapsulat. ing the pores composed of HDPE aggregates, playing as a kind of compatibilizer. In addition, the polymer aggre. gates of the HDPE membrane were proved to be composed of bulky coagulated particles making a large room among them, while that of HDPE / SHB membrane is composed of rather densely coagulated fibrillar bundles.

\section{References}

1. F. Nagoya, H. Ohyagi, S. Matsuda, and K. Okajima, to be submitted.

2. D. R. Norton and A. Keller, Polymer, 26, 704 (1985).

3. G. Kanig, Colloid Polym. Sci., 261, 373 (1983).

4. J. S. Trent, M. J. Schneider, and I. G. Voigt-Martin, J. Polym. Sci., Polym. Phys. ed., 18, 1361 (1980).

5. D. Montezions, B. G. Wells, and J. L. Burns, J. Polym. Sci., Polym. Lett. ed., 23. 421 (1985).

6. H. Sano, T. Usami, and H. Nakagawa, Polymer, 27. 1497 (1986). 